\title{
Existence of fixed points for $\Theta$-type contraction and $\Theta$-type Suzuki contraction in complete metric spaces
}

\author{
Xin-dong Liu', Shih-sen Chang ${ }^{2^{*}}$, Yun Xiao ${ }^{1}$ and Liang Cai Zhao'
}

\begin{tabular}{l}
\hline${ }^{\text {*Correspondence: }}$ \\
changss2013@163.com \\
${ }^{2}$ Center for General Education, \\
China Medical University, Taichung, \\
40402 , Taiwan \\
Full list of author information is \\
available at the end of the article
\end{tabular}

available at the end of the article

\begin{abstract}
The purpose of this paper is to introduce the notions of $\Theta$-type contractions and $\Theta$-type Suzuki contractions and to establish some new fixed point theorems for these two kinds of mappings in the setting of complete metric spaces. The results presented in the paper are an extension of the Banach contraction principle, the Suzuki contraction theorem, and the Jleli and Samet fixed point theorem. As an application, we utilize our results to study the existence problem of solutions of nonlinear Hammerstein integral equations.
\end{abstract}

MSC: 47H09; 49M05; 47H10

Keywords: Banach contraction principle; fixed point; $\Theta$-type contraction; $\Theta$-type Suzuki contraction

\section{Introduction and preliminaries}

Let $(X, d)$ be a complete metric space and $T: X \rightarrow X$ be a mapping. If there exists $k \in(0,1)$ such that for all $x, y \in X, d(T x, T y) \leq k d(x, y)$, then $T$ is said to be a contractive mapping. In 1922, Polish mathematician Banach [1] proved a very important result regarding a contraction mapping, known as the Banach contraction principle. It is one of the fundamental results in fixed point theory. Due to its importance and simplicity, several authors have obtained many interesting extensions of the Banach contraction principle (see [2-8] and the references therein).

In 2009, Suzuki [2] proved the following generalized Banach contraction principle in compact metric spaces.

Theorem 1.1 [2] Let $(X, d)$ be a compact metric space and $T: X \rightarrow X$ be a mapping. Assume that, for all $x, y \in X$ with $x \neq y$,

$$
\frac{1}{2} d(x, T x)<d(x, y) \quad \Longrightarrow \quad d(T x, T y)<d(x, y) .
$$

Then $T$ has a unique fixed point in $X$.

In 2014, Jleli and Samet $[9,10]$ introduced the following notion of a $\theta$-contraction.

(c) 2016 Liu et al. This article is distributed under the terms of the Creative Commons Attribution 4.0 International License (http://creativecommons.org/licenses/by/4.0/), which permits unrestricted use, distribution, and reproduction in any medium, provided you give appropriate credit to the original author(s) and the source, provide a link to the Creative Commons license, and indicate if changes were made. 
Definition 1.2 [10] Let $(X, d)$ be a metric space. A mapping $T: X \rightarrow X$ is said to be a $\theta$-contraction, if there exists $k \in(0,1)$ such that

$$
x, y \in X, \quad d(T x, T y) \neq 0 \quad \Longrightarrow \quad \theta(d(T x, T y)) \leq[\theta(d(x, y))]^{k}
$$

where $\theta:(0, \infty) \rightarrow(1, \infty)$ is a function satisfying the following conditions:

$\left(\Theta_{1}\right) \theta$ is non-decreasing;

$\left(\Theta_{2}\right)$ for each sequence $\left\{t_{n}\right\} \subset(0, \infty), \lim _{n \rightarrow \infty} \theta\left(t_{n}\right)=1$ iff $\lim _{n \rightarrow \infty} t_{n}=0$;

$\left(\Theta_{3}\right)$ there exist $r \in(0,1)$ and $l \in(0, \infty]$ such that $\lim _{t \rightarrow 0^{+}} \frac{\theta(t)-1}{t^{r}}=l$;

$\left(\Theta_{4}\right) \theta$ is continuous.

In the sequel we denote by $\Theta$ the set of all functions satisfying the conditions $\left(\Theta_{1}\right)-\left(\Theta_{4}\right)$. By using the notion of a $\theta$-contraction, Jleli et al. [10] proved the following fixed point theorem.

Theorem 1.3 (Jleli et al. [10]) Let $(X, d)$ be a complete metric space and $T: X \rightarrow X$ be a $\theta$-contraction, then $T$ has a unique fixed point in $X$.

Remark 1.4 It is obvious that Theorem 1.3 is a modified version of the Banach contraction principle. In fact, if $T: X \rightarrow X$ is a Banach contractive mapping with a contractive constant $\lambda \in(0,1)$, i.e.,

$$
d(T x, T y) \leq \lambda d(x, y), \quad \forall x, y \in X
$$

Since $\theta(t)=e^{\sqrt{t}} \in \Theta, t>0$, by passing it to the above inequality, we arrive at

$$
e^{\sqrt{d(T x, T y)}} \leq e^{\sqrt{\lambda d(x, y)}}=\left[e^{\sqrt{d(x, y)}}\right]^{\sqrt{\lambda}}=\left[e^{\sqrt{d(x, y)}}\right]^{k}, \quad \forall x, y \in X,
$$

where $k=\sqrt{\lambda}$. It follows from Theorem 1.3 that $T$ has a unique fixed point in $X$.

From Theorem 1.3 it is natural to put forward the following open question.

Open question Could we obtain some fixed point theorems for $\theta$-contractive mappings without the conditions $\left(\Theta_{2}\right)$ and $\left(\Theta_{3}\right)$ ?

In order to give an affirmative answer to this open question, we first analyze the conditions $\left(\Theta_{2}\right)$ and $\left(\Theta_{3}\right)$.

It is easy to see that the condition $\left(\Theta_{3}\right)$ is so strong that there exist a lot of functions which satisfy the conditions $\left(\Theta_{1}\right),\left(\Theta_{2}\right)$, and $\left(\Theta_{4}\right)$ but they not the condition $\left(\Theta_{3}\right)$. For example, we can prove that the function $\theta(t)=e^{e^{-\frac{1}{t^{p}}}}, p>0$ satisfies the conditions $\left(\Theta_{1}\right),\left(\Theta_{2}\right)$, and $\left(\Theta_{4}\right)$, but, for any $r>0$,

$$
\lim _{t \rightarrow 0^{+}} \frac{\theta(t)-1}{t^{r}}=\lim _{t \rightarrow 0^{+}} \frac{e^{e^{-\frac{1}{t^{p}}}-1}}{t^{r}}=\lim _{t \rightarrow 0^{+}} \frac{e^{-\frac{1}{t^{p}}}}{t^{r}}=\lim _{t \rightarrow 0^{+}} \frac{\frac{1}{t^{r}}}{e^{\frac{1}{t^{p}}}}=0,
$$

i.e., it does not satisfy the condition $\left(\Theta_{3}\right)$. 
Furthermore, the condition $\left(\Theta_{2}\right)$ can be replaced by an equivalent but a more simple condition $\inf _{t \in(0, \infty)} \theta(t)=1$. This fact can be seen from the following lemmas.

Lemma 1.5 [11] If $\left\{t_{k}\right\}_{k}$ is a bounded sequence of real numbers such that all its convergent subsequences have the same limit $l$, then $\left\{t_{k}\right\}_{k}$ is convergent and $\lim _{k \rightarrow \infty} t_{k}=l$.

Lemma 1.6 Let $\theta:(0, \infty) \rightarrow(1, \infty)$ be a non-decreasing and continuous function with $\inf _{t \in(0, \infty)} \theta(t)=1$ and $\left\{t_{k}\right\}_{k}$ be a sequence in $(0, \infty)$. Then the following conclusion holds:

$$
\lim _{k \rightarrow \infty} \theta\left(t_{k}\right)=1 \Longleftrightarrow \lim _{k \rightarrow \infty} t_{k}=0
$$

Proof (1) (Necessity) If $\lim _{k \rightarrow \infty} \theta\left(t_{k}\right)=1$, then we claim that the sequence $\left\{t_{k}\right\}$ is bounded. Indeed, if the sequence is unbounded, we may assume that $t_{k} \rightarrow \infty$, then for every $M>0$, there is $k_{0} \in \mathbb{N}$ such that $t_{k}>M$ for any $k>k_{0}$. Hence we have $\theta(M) \leq \theta\left(t_{k}\right)$, and so

$$
\theta(M) \leq \lim _{k \rightarrow \infty} \theta\left(t_{k}\right)=1
$$

which is a contradiction with $\theta(M)>1$. Therefore $\left\{t_{k}\right\}$ is bounded. Hence there exists a subsequence $\left\{t_{k_{n}}\right\} \subset\left\{t_{k}\right\}$ such that $\lim _{n \rightarrow \infty} t_{k_{n}}=\alpha$ (some nonnegative number). Clearly $\alpha \geq 0$.

If $\alpha>0$, then there exists $n_{0} \in \mathbb{N}$ such that $t_{k_{n}} \in\left(\frac{\alpha}{2}, \frac{3 \alpha}{2}\right)$ for all $n \geq n_{0}$. As $\theta$ is nondecreasing, we deduce that $\theta\left(\frac{\alpha}{2}\right) \leq \lim _{n \rightarrow \infty} \theta\left(t_{k_{n}}\right)=1$ which contradicts with $\theta\left(\frac{\alpha}{2}\right)>1$. Consequently $\alpha=0$. By Lemma 1.5 , we know that $\lim _{k \rightarrow \infty} t_{k}=0$.

(2) (Sufficiency) Since $\inf _{t \in(0, \infty)} \theta(t)=1$, if $t_{k} \rightarrow 0$, then for any given $\epsilon>0$, there is $\alpha>0$ such that $\theta(\alpha) \in(1,1+\epsilon)$ and there exists $k_{1} \in \mathbb{N}$ such that $t_{k}<\alpha$ for all $k>k_{1}$. Therefore $1<\theta\left(t_{k}\right) \leq \theta(\alpha)<1+\epsilon$, for $k>k_{1}$. This shows that $\theta\left(t_{k}\right) \rightarrow 1$.

The conclusion of Lemma 1.6 is proved.

In the sequel, we denote by $\tilde{\Theta}$ the set of functions $\theta:(0, \infty) \rightarrow(1, \infty)$ satisfying the following conditions:

$\left(\Theta_{1}\right)^{\prime} \theta$ is non-decreasing and continuous;

$\left(\Theta_{2}\right)^{\prime} \inf _{t \in(0, \infty)} \theta(t)=1$.

Examples of functions belonging to $\tilde{\Theta}$ It is obvious that the following are examples of the functions belonging to $\tilde{\Theta}$ :

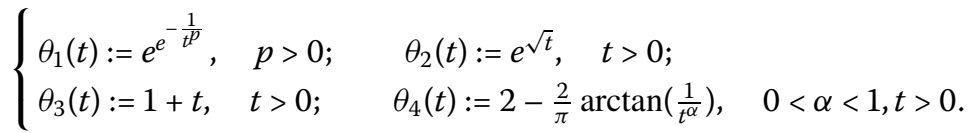

Based on the above argument, now we are in a position to give the following definition.

Definition 1.7 Let $(X, d)$ be a complete metric space and $T: X \rightarrow X$ be a mapping.

(1) $T$ is said to be a $\theta$-type contraction, if there exist $k \in(0,1)$ and $\theta \in \tilde{\Theta}$ such that

$$
\forall x, y \in X, \quad d(T x, T y)>0 \quad \Longrightarrow \quad \theta(d(T x, T y)) \leq[\theta(M(x, y))]^{k}
$$


(2) $T$ is said to be a $\theta$-type Suzuki contraction, if there exist $k \in(0,1)$ and $\theta \in \tilde{\Theta}$ such that for all $x, y \in X$ with $T x \neq T y$,

$$
\frac{1}{2} d(x, T x)<d(x, y) \quad \Longrightarrow \quad \theta(d(T x, T y)) \leq[\theta(M(x, y))]^{k}
$$

where

$$
M(x, y)=\max \left\{d(x, y), d(x, T x), d(y, T y), \frac{1}{2} d(x, T y), d(y, T x)\right\} .
$$

The purpose of this paper is to prove some existence theorems of fixed points for $\theta$-type contraction and $\theta$-type Suzuki contraction in the setting of complete metric spaces. The results presented in the paper improve and extend the corresponding results in Banach [1], Suzuki [2], Jleli and Samet $[9,10]$. As an application, we shall utilize our results to study the existence problem of solutions for a class of nonlinear Hammerstein integral equations.

\section{Existence theorems of fixed point for $\theta$-type Suzuki contractions and $\theta$-type contractions}

In this section, we are going to give some existence theorems of fixed point for $\theta$-type Suzuki contractions and $\theta$-type contractions.

Theorem 2.1 Let $(X, d)$ be a complete metric space and $T: X \rightarrow X$ be a $\theta$-type Suzuki contraction, i.e., there exist $\theta \in \tilde{\Theta}$ and $k \in(0,1)$ such that for all $x, y \in X$ with $T x \neq T y$,

$$
\frac{1}{2} d(x, T x)<d(x, y) \quad \Longrightarrow \quad \theta(d(T x, T y)) \leq[\theta(M(x, y))]^{k},
$$

where

$$
M(x, y):=\max \left\{d(x, y), d(x, T x), d(y, T y), \frac{1}{2} d(x, T y), d(y, T x)\right\},
$$

then $T$ has a unique fixed point $z \in X$ and for each $x \in X$ the sequence $\left\{T^{n} x\right\}$ converges to $z$.

Proof Let $x$ be an arbitrary point in $X$. If for some positive integer $p$ such that $T^{p-1} x=T^{p} x$, then $T^{p-1} x$ will be a fixed point of $T$. So, without loss of generality, we can assume that $d\left(T^{n-1} x, T^{n} x\right)>0$ for all $n \geq 1$.

Therefore,

$$
\frac{1}{2} d\left(T^{n-1} x, T^{n} x\right)<d\left(T^{n-1} x, T^{n} x\right), \quad \forall n \geq 1 .
$$

Hence from (2.1), for all $n \geq 1$, we have

$$
\theta\left(d\left(T T^{n-1} x, T T^{n} x\right)\right)=\theta\left(d\left(T^{n} x, T^{n+1} x\right)\right) \leq\left[\theta\left(M\left(T^{n-1} x, T^{n} x\right)\right)\right]^{k},
$$

where

$$
\begin{aligned}
M\left(T^{n-1} x, T^{n} x\right)= & \max \left\{d\left(T^{n-1} x, T^{n} x\right), d\left(T^{n-1} x, T^{n} x\right), d\left(T^{n} x, T^{n+1} x\right),\right. \\
& \left.\frac{1}{2} d\left(T^{n-1} x, T^{n+1} x\right), d\left(T^{n} x, T^{n} x\right)\right\}
\end{aligned}
$$




$$
\begin{aligned}
& =\max \left\{d\left(T^{n-1} x, T^{n} x\right), d\left(T^{n} x, T^{n+1} x\right), \frac{1}{2} d\left(T^{n-1} x, T^{n+1} x\right)\right\} \\
& =\max \left\{d\left(T^{n-1} x, T^{n} x\right), d\left(T^{n} x, T^{n+1} x\right)\right\} .
\end{aligned}
$$

If $M\left(T^{n-1} x, T^{n} x\right)=d\left(T^{n} x, T^{n+1} x\right)$, then it follows from (2.4) that

$$
\theta\left(d\left(T^{n} x, T^{n+1} x\right)\right) \leq\left[\theta\left(d\left(T^{n} x, T^{n+1} x\right)\right)\right]^{k} .
$$

This implies that

$$
\ln \left[\theta\left(d\left(T^{n} x, T^{n+1} x\right)\right)\right] \leq k \ln \left[\theta\left(d\left(T^{n} x, T^{n+1} x\right)\right)\right]
$$

which is a contradiction with $k \in(0,1)$. Hence, from $(2.5)$ we have $M\left(T^{n-1} x, T^{n} x\right)=$ $d\left(T^{n-1} x, T^{n} x\right)$. This together with inequality (2.4) yields

$$
\begin{aligned}
\theta\left(d\left(T^{n} x, T^{n+1} x\right)\right) & \leq\left[\theta\left(d\left(T^{n-1} x, T^{n} x\right)\right)\right]^{k} \leq\left[\theta\left(d\left(T^{n-2} x, T^{n-1} x\right)\right)\right]^{k^{2}} \\
& \leq \cdots \leq[\theta(d(x, T x))]^{k^{n}}
\end{aligned}
$$

Since $\theta:(0, \infty) \rightarrow(1, \infty)$, it follows from $(2.6)$ that

$$
1 \leq \lim _{n \rightarrow \infty} \theta\left(d\left(T^{n} x, T^{n+1} x\right)\right) \leq \lim _{n \rightarrow \infty}[\theta(d(x, T x))]^{k^{n}}=1 .
$$

Therefore we have $\lim _{n \rightarrow \infty} \theta\left(d\left(T^{n} x, T^{n+1} x\right)\right)=1$. This together with $\left(\Theta_{2}\right)^{\prime}$ and Lemma 1.6 gives

$$
\lim _{n \rightarrow \infty} d\left(T^{n} x, T^{n+1} x\right)=0 .
$$

Now, we claim that $\left\{T^{n} x\right\}_{n=1}^{\infty}$ is a Cauchy sequence. Arguing by contradiction, we assume that there exist $\epsilon>0$ and a sequence $\left\{p_{n}\right\}_{n=1}^{\infty}$ and $\left\{q_{n}\right\}_{n=1}^{\infty}$ of natural numbers such that

$$
p_{n}>q_{n}>n, \quad d\left(T^{p_{n}} x, T^{q_{n}} x\right) \geq \epsilon, \quad d\left(T^{p_{n}-1} x, T^{q_{n}} x\right)<\epsilon, \quad \forall n \in \mathbb{N} .
$$

So, we have

$$
\begin{aligned}
\epsilon & \leq d\left(T^{p_{n}} x, T^{q_{n}} x\right) \leq d\left(T^{p_{n}} x, T^{p_{n}-1} x\right)+d\left(T^{p_{n}-1} x, T^{q_{n}} x\right) \\
& \leq d\left(T^{p_{n}} x, T^{p_{n}-1} x\right)+\epsilon .
\end{aligned}
$$

It follows from (2.7) and the above inequality that

$$
\lim _{n \rightarrow \infty} d\left(T^{p_{n}} x, T^{q_{n}} x\right)=\epsilon
$$

From (2.7) and (2.9), we can choose a positive integer $n_{0} \geq 1$ such that

$$
\frac{1}{2} d\left(T^{p_{n}} x, T T^{p_{n}} x\right)<\frac{1}{2} \epsilon<d\left(T^{p_{n}} x, T^{q_{n}} x\right), \quad \forall n \geq n_{0} .
$$


So, from the assumption of the theorem, we get

$$
\theta\left(d\left(T^{p_{n}+1} x, T^{q_{n}+1} x\right)\right) \leq\left[\theta\left(M\left(T^{p_{n}} x, T^{q_{n}} x\right)\right)\right]^{k}, \quad \forall n \geq n_{0},
$$

where

$$
\begin{aligned}
M\left(T^{p_{n}} x, T^{q_{n}} x\right)= & \max \left\{d\left(T^{p_{n}} x, T^{q_{n}} x\right), d\left(T^{p_{n}} x, T^{p_{n}+1} x\right), d\left(T^{q_{n}} x, T^{q_{n}+1} x\right),\right. \\
& \left.\frac{1}{2} d\left(T^{p_{n}} x, T^{q_{n}+1} x\right), d\left(T^{q_{n}} x, T^{p_{n}+1} x\right)\right\} \\
\leq & \max \left\{d\left(T^{p_{n}} x, T^{p_{n}+1} x\right), d\left(T^{q_{n}} x, T^{q_{n}+1} x\right),\right. \\
& \left.d\left(T^{p_{n}} x, T^{p_{n}+1} x\right)+d\left(T^{p_{n}+1} x, T^{q_{n}+1} x\right)+d\left(T^{q_{n}+1} x, T^{q_{n}} x\right)\right\} .
\end{aligned}
$$

Substituting (2.11) into (2.10), then letting $n \rightarrow \infty$ and by using the condition $\left(\Theta_{2}\right)^{\prime},(2.7)$, (2.9), we get

$$
\lim _{n \rightarrow \infty} \theta\left(d\left(T^{p_{n}+1} x, T^{q_{n}+1} x\right)\right) \leq \lim _{n \rightarrow \infty}\left[\theta\left(d\left(T^{p_{n}+1} x, T^{q_{n}+1} x\right)\right)\right]^{k} .
$$

This is a contradiction. Therefore $\left\{T^{n} x\right\}_{n=1}^{\infty}$ is a Cauchy sequence. By the completeness of $(X, d)$, without loss of generality, we can assume that $\left\{T^{n} x\right\}_{n=1}^{\infty}$ converges to some point $z \in X$, i.e.,

$$
\lim _{n \rightarrow \infty} d\left(T^{n} x, z\right)=0
$$

Now, we claim that

$$
\frac{1}{2} d\left(T^{n+1} x, T^{n+2} x\right)<d\left(T^{n+1} x, z\right), \quad \forall n \in \mathbb{N} .
$$

Suppose to the contrary that (2.13) is not true. Therefore the following inequality is also not true:

$$
\frac{1}{2} d\left(T^{n} x, T^{n+1} x\right)<d\left(T^{n} x, z\right), \quad \forall n \in \mathbb{N} .
$$

It follows from (2.13) and (2.14) that there exists an $m \in \mathbb{N}$ such that

$$
\frac{1}{2} d\left(T^{m} x, T^{m+1} x\right) \geq d\left(T^{m} x, z\right) \quad \text { and } \quad \frac{1}{2} d\left(T^{m+1} x, T^{m+2} x\right) \geq d\left(T^{m+1} x, z\right) .
$$

Therefore,

$$
2 d\left(T^{m} x, z\right) \leq d\left(T^{m} x, T^{m+1} x\right) \leq d\left(T^{m} x, z\right)+d\left(z, T^{m+1} x\right) .
$$

This implies that

$$
d\left(T^{m} x, z\right) \leq d\left(z, T^{m+1} x\right) .
$$

This together with (2.15) shows that

$$
d\left(T^{m} x, z\right) \leq d\left(z, T^{m+1} x\right) \leq \frac{1}{2} d\left(T^{m+1} x, T^{m+2} x\right) .
$$


Since $\frac{1}{2} d\left(T^{m} x, T^{m+1} x\right)<d\left(T^{m} x, T^{m+1} x\right)$, by the assumption of the theorem, we get

$$
\theta\left(d\left(T^{m+1} x, T^{m+2} x\right)\right) \leq\left[\theta\left(M\left(T^{m} x, T^{m+1} x\right)\right)\right]^{k}
$$

where

$$
\begin{aligned}
M\left(T^{m} x, T^{m+1} x\right)= & \max \left\{d\left(T^{m} x, T^{m+1} x\right), d\left(T^{m} x, T T^{m} x\right), d\left(T^{m+1} x, T T^{m+1} x\right),\right. \\
& \left.\frac{1}{2} d\left(T^{m} x, T T^{m+1} x\right), d\left(T^{m+1} x, T T^{m} x\right)\right\} \\
= & \max \left\{d\left(T^{m} x, T^{m+1} x\right), d\left(T^{m} x, T^{m+1} x\right), d\left(T^{m+1} x, T^{m+2} x\right)\right. \\
& \left.\frac{1}{2} d\left(T^{m} x, T^{m+1} x\right)+d\left(T^{m+1} x, T^{m+2} x\right)\right\} \\
= & \max \left\{d\left(T^{m} x, T^{m+1} x\right), d\left(T^{m+1} x, T^{m+2} x\right)\right\} .
\end{aligned}
$$

If $M\left(T^{m} x, T^{m+1} x\right)=d\left(T^{m+1} x, T^{m+2} x\right)$, then from (2.18) we have

$$
\theta\left(d\left(T^{m+1} x, T^{m+2} x\right)\right) \leq\left[\theta\left(d\left(T^{m+1} x, T^{m+2} x\right)\right)\right]^{k}<\theta\left(d\left(T^{m+1} x, T^{m+2} x\right)\right) .
$$

This is a contradiction. Therefore we have

$$
M\left(T^{m} x, T^{m+1} x\right)=d\left(T^{m} x, T^{m+1} x\right) .
$$

Consequently, from (2.18) we have

$$
\theta\left(d\left(T^{m+1} x, T^{m+2} x\right)\right) \leq\left[\theta\left(d\left(T^{m} x, T^{m+1} x\right)\right)\right]^{k} .
$$

Since $k \in(0,1)$, we have

$$
\left[\theta\left(d\left(T^{m} x, T^{m+1} x\right)\right)\right]^{k}<\theta\left(d\left(T^{m} x, T^{m+1} x\right)\right) .
$$

Hence from condition $\left(\Theta_{1}\right)^{\prime}$ and (2.19) we have

$$
d\left(T^{m+1} x, T^{m+2} x\right)<d\left(T^{m} x, T^{m+1} x\right)
$$

This together with (2.17) shows that

$$
\begin{aligned}
d\left(T^{m+1} x, T^{m+2} x\right) & <d\left(T^{m} x, T^{m+1} x\right) \\
& \leq d\left(T^{m} x, z\right)+d\left(z, T^{m+1} x\right) \\
& \leq \frac{1}{2} d\left(T^{m+1} x, T^{m+2} x\right)+\frac{1}{2} d\left(T^{m+1} x, T^{m+2} x\right) \\
& =d\left(T^{m+1} x, T^{m+2} x\right)
\end{aligned}
$$

which is a contradiction. Therefore the inequality (2.13) is proved. 
By the assumption of Theorem 2.1 and (2.13) we have, for every $n \in \mathbb{N}$,

$$
\theta\left(d\left(T T^{n+1} x, T z\right)\right) \leq\left[\theta\left(M\left(T^{n+1} x, z\right)\right)\right]^{k} .
$$

On the other hand, from (2.12) we know that $T^{n} x \rightarrow z$, hence we have

$$
\begin{aligned}
M\left(T^{n+1} x, z\right)= & \max \left\{d\left(T^{n+1} x, z\right), d\left(T^{n+1} x, T T^{n+1} x\right), d(z, T z),\right. \\
& \left.\frac{1}{2} d\left(T^{n+1} x, T z\right), d\left(T z, T T^{n+1} x\right)\right\} \\
\rightarrow & d(z, T z) \quad(\text { as } n \rightarrow \infty) .
\end{aligned}
$$

Now, we claim that $d(z, T z)=0$.

In fact, if $d(z, T z)>0$. Letting $n \rightarrow \infty$ in (2.22), and by using (2.12), (2.23), and the condition $\left(\Theta_{1}\right)^{\prime}$, we obtain

$$
\begin{aligned}
\theta(d(z, T z)) & =\lim _{n \rightarrow \infty} \theta\left(d\left(T T^{n+1} x, T z\right)\right) \\
& \leq \lim _{n \rightarrow \infty}\left[\theta\left(M\left(T^{n+1} x, z\right)\right)\right]^{k} \\
& =[\theta(d(z, T z))]^{k} \\
& <\theta(d(z, T z)) .
\end{aligned}
$$

This is a contradiction. Hence, $z=T z$, i.e., $z$ is a fixed point of $T$.

Now we prove that $z$ is the unique fixed point of $T$ in $X$. In fact, if $z, u \in X$ are two distinct fixed points of $T$, that is $T z=z \neq u=T u$, then $d(z, u)=d(T z, T u)>0$. Since $0=\frac{1}{2} d(z, T z)<$ $d(z, u)$, as follows from the assumption of the theorem, we obtain

$$
\theta(d(z, u))=\theta(d(T z, T u)) \leq[\theta(M(z, u))]^{k},
$$

where

$$
M(z, u)=\max \left\{d(z, u), d(z, T z), d(u, T u), \frac{1}{2} d(z, T u), d(u, T z)\right\}=d(z, u) .
$$

This together with (2.24) shows that

$$
\theta(d(z, u))=\theta(d(T z, T u)) \leq[\theta(d(z, u))]^{k}<\theta(d(z, u)),
$$

which is a contraction. Hence we have $u=v$.

This completes the proof of Theorem 2.1.

Remark 2.2 Theorem 2.1 is a generalization and improvement of the main results in Suzuki [2].

It follows from Definition 1.7 that if $T: X \rightarrow X$ is a $\theta$-type contraction, then $T: X \rightarrow$ $X$ is a $\theta$-type Suzuki contraction. Hence from Theorem 2.1 we can obtain the following existence theorem of fixed point for $\theta$-type contractions. 
Theorem 2.3 Let $(X, d)$ be a complete metric space and $T: X \rightarrow X$ be a $\theta$-type contractive mapping, i.e., there exist $\theta \in \tilde{\Theta}$ and $k \in(0,1)$ such that

$$
x, y \in X, \quad d(T x, T y) \neq 0 \quad \Longrightarrow \quad \theta(d(T x, T y)) \leq[\theta(M(x, y))]^{k},
$$

where

$$
M(x, y):=\max \left\{d(x, y), d(x, T x), d(y, T y), \frac{1}{2} d(x, T y), d(y, T x)\right\},
$$

then $T$ has a unique fixed point $z \in X$, and for each $x \in X$ the sequence $\left\{T^{n} x\right\}$ converges to $z$.

Remark 2.4 Theorem 2.3 is a generalization and improvement of the Banach contraction principle [1] and some recent results in Jleli and Samet $[9,10]$.

\section{Some consequences}

Corollary 3.1 Let $(X, d)$ be a complete metric space and $T: X \rightarrow X$ be a mapping. If there exists $\lambda \in(0,1)$ such that

$$
d(T x, T y) \leq \lambda M(x, y), \quad \forall x, y \in X
$$

where

$$
M(x, y)=\max \left\{d(x, y), d(x, T x), d(y, T y), \frac{1}{2} d(x, T y), d(y, T x)\right\},
$$

then $T$ has a unique fixed point $z \in X$ and for any given $x \in X$, the sequence $\left\{T^{n} x\right\}$ converges to $z$.

Proof Denote by $\theta(t):=e^{\sqrt{t}}:(0, \infty) \rightarrow(1, \infty)$. It is easy to check that $\theta \in \tilde{\Theta}$. Hence from (3.1) we have

$$
e^{\sqrt{d(T x, T y)}} \leq\left[e^{\sqrt{\lambda M(x, y)}}\right]=\left[e^{\sqrt{M(x, y)}}\right]^{\sqrt{\lambda}} .
$$

This implies that $T$ is a $\theta$-type contractive mapping with $k=\sqrt{\lambda}$. Therefore the conclusion of Corollary 3.1 can be obtained from Theorem 2.3 immediately.

The following corollary can be obtained from Corollary 3.1 immediately.

Corollary 3.2 Let $(X, d)$ be a complete metric space and $T: X \rightarrow X$ be a mapping. Suppose that there exist $\lambda, \mu, v, \xi, \eta \geq 0$ with $\lambda+\mu+v+\xi+\eta<1$ such that

$$
d(T x, T y) \leq \lambda d(x, y)+\mu d(x, T x)+v d(y, T y)+\xi \frac{1}{2} d(x, T y)+\eta d(y, T x), \quad \forall x, y \in X .
$$

Then $T$ has a unique fixed point $z$ and, for each $x \in X$, the sequence $\left\{T^{n} x\right\}$ converges to $z$.

We note that if $p>0$, then $\theta(t)=e^{e^{-\frac{1}{x^{p}}}} \in \tilde{\Theta}$. Hence from Theorem 2.3 we can obtain the following corollary. 
Corollary 3.3 Let $(X, d)$ be a complete metric space and $T: X \rightarrow X$ be a mapping. Suppose that there exist $p>0, k \in(0,1)$ such that

$$
e^{e^{-\frac{1}{[d(T x, T Y)]^{p}}}} \leq\left[e^{e^{-\frac{1}{[M(x, y)]^{p}}}}\right]^{k}, \quad \forall x, y \in X, T x \neq T y,
$$

where $M(x, y)$ is given by (3.2). Then $T$ has a unique fixed point $z$ and, for each $x \in X$, the sequence $\left\{T^{n} x\right\}$ converges to $z$.

\section{Application to nonlinear Hammerstein integral equations}

As an application, in this section, we shall use the fixed point theorems proved in Section 2 to study the existence and uniqueness problem of solutions for some kind of nonlinear Hammerstein integral equations.

Let us consider the following nonlinear Hammerstein integral equation:

$$
x(t)=h(t)+\int_{0}^{t} K(t, s) f(s, x(s)) d s,
$$

where the unknown function $x(t)$ takes real values.

Let $X=C([0, E])$ be the space of all real continuous functions defined on $[0, E]$. It is well known that $C([0, E])$ endowed with the metric

$$
d(x, y)=\|x-y\|=\max _{t \in[0, E]}|x(t)-y(t)|
$$

is a complete metric space. Define a mapping $T: X \rightarrow X$ by

$$
T(x)(t)=h(t)+\int_{0}^{t} K(t, s) f(s, x(s)) d s, \quad \forall t \in[0, E] .
$$

\section{Assumption 4.1}

(I) $f \in C([0, E] \times(-\infty,+\infty)), h \in X$, and $K \in C([0, E]) \times([0, E])$ such that $K(t, s) \geq 0$;

(II) $f(t, \cdot):(-\infty,+\infty) \rightarrow(-\infty,+\infty)$ is increasing for all $t \in[0, E]$;

(III) there exists $\tau \in[1,+\infty)$ such that

$$
|f(t, x)-f(t, y)| \leq \tau e^{-\tau} Q(x, y), \quad \forall x, y \in X, t \in[0, E],
$$

where $Q(x, y):=\max \left\{|x-y|,|x-T x|,|y-T y|, \frac{1}{2}|x-T y|,|y-T x|\right\} ;$

(IV) $\max _{t, s \in[0, E]}|K(t, s)| \leq 1$.

For $x \in X$, we defined $\|x\|_{\tau}=\max _{t \in[0, E]}|x(t)| e^{-\tau t}$, where $\tau \geq 1$ is chosen arbitrarily. It is easy to check that $\|\cdot\|_{\tau}$ is a norm equivalent to the maximum norm $\|\cdot\|$ in $X$, and $X$ endowed with the metric $d_{\tau}$ defined by

$$
d_{\tau}(x, y)=\|x-y\|_{\tau}=\max _{t \in[0, E]}\left\{|x(t)-y(t)| e^{-\tau t}\right\}, \quad x, y \in X,
$$

is a complete metric space. 
Theorem 4.1 Let $X=C([0, E]),\left(X, d_{\tau}\right), T, f, K(t, s)$ be the same as above. If Assumption 4.1 is satisfied, then the nonlinear Hammerstein integral equation (4.1) has a unique solution $x^{*} \in C([0, E])$, and for each $x \in C([0, E])$ the iterative sequence $\left\{x_{n}=T^{n} x\right\}$ converges to the unique solution $x^{*} \in X$ of equation (4.1).

Proof We first show that the mapping $T: X \rightarrow X$ defined by (4.2) is a $\theta$-type contraction. Indeed, from the conditions (III) and (IV), for each $x, y \in C([0, E]), t \in[0, E]$, we have

$$
\begin{aligned}
|T x(t)-T y(t)|= & \left|\int_{0}^{t} K(t, s)(f(s, x(s))-f(s, y(s))) d s\right| \\
\leq & \int_{0}^{t}|K(t, s)| f(s, x(s))-f(s, y(s)) \mid d s \\
\leq & \int_{0}^{t}|f(s, x(s))-f(s, y(s))| d s \\
\leq & \int_{0}^{t} \tau e^{-\tau} Q(x(s), y(s)) d s \\
= & \tau e^{-\tau} \int_{0}^{t} e^{s \tau} \max \left\{|x(s)-y(s)| e^{-s \tau},|x(s)-T x(s)| e^{-s \tau},\right. \\
& \left.|y(s)-T y(s)| e^{-s \tau}, \frac{1}{2}|x(s)-T y(s)| e^{-s \tau},|y(s)-T x(s)| e^{-s \tau}\right\} d s \\
\leq & \tau e^{-\tau} \int_{0}^{t} e^{s \tau} \max \left\{d_{\tau}(x, y), d_{\tau}(x, T x),\right. \\
& \left.d_{\tau}(y, T y), \frac{1}{2} d_{\tau}(x, T y), d_{\tau}(y, T x)\right\} d s \\
= & \tau e^{-\tau} M(x, y) \int_{0}^{t} e^{s \tau} d s \\
= & \tau e^{-\tau} M(x, y) \frac{e^{\tau t}}{\tau}=e^{-\tau(1-t)} M(x, y),
\end{aligned}
$$

where

$$
M(x, y)=\max \left\{d_{\tau}(x, y), d_{\tau}(x, T x), d_{\tau}(y, T y), \frac{1}{2} d_{\tau}(x, T y), d_{\tau}(y, T x)\right\} .
$$

This implies that $|T x(t)-T y(t)| e^{-\tau t} \leq e^{-\tau} M(x, y)$. Hence we have

$$
d_{\tau}(T x, T y)=\max _{t \in[0, E]}\left\{|T x(t)-T y(t)| e^{-\tau t}\right\} \leq e^{-\tau} M(x, y) .
$$

Since $\theta(t)=e^{\sqrt{t}} \in \tilde{\Theta}, t>0$, we have

$$
e^{\sqrt{d_{\tau}(T x, T y)}} \leq e^{\sqrt{e^{-\tau} M(x, y)}}=\left[e^{\sqrt{M(x, y)}}\right]^{k}, \quad \forall x, y \in X,
$$

where $k=\sqrt{e^{-\tau}}$. Since $\tau \geq 1, k \in(0,1)$. Therefore the mapping $T$ is a $\theta$-type contraction. By Theorem 2.3, $T$ has a unique fixed point $x^{*} \in X$, i.e., $x^{*}$ is the unique solution of the nonlinear Hammerstein integral equation (4.1) and, for each $x \in X$, the sequence $\left\{x_{n}=\right.$ $\left.T^{n} x\right\}$ converges uniformly to $x^{*}$. 
Competing interests

The authors declare that they have no competing interests.

Authors' contributions

All authors contributed equally to the writing of this paper. All authors read and approved the final manuscript.

\section{Author details}

${ }^{1}$ Institute of Mathematics, Yibin University, Yibin, Sichuan 644000, China. ${ }^{2}$ Center for General Education, China Medical University, Taichung, 40402, Taiwan.

\section{Acknowledgements}

The authors would like to express their thanks to the editor and the referees for their helpful comments and advices. This work was supported by Scientific Research Fund of SiChuan Provincial Education Department (No. 14ZA0272). This work was also supported by the National Natural Science Foundation of China (Grant No. 11361070) and the Natural Science Foundation of China Medical University, Taiwan.

Received: 29 May 2015 Accepted: 4 January 2016 Published online: 13 January 2016

\section{References}

1. Banach, B: Sur les opérations dons les ensembles abstraits et leur application aux équations intégrales. Fundam. Math. 3, 133-181 (1922)

2. Suzuki, T: A new type of fixed point theorem in metric spaces. Nonlinear Anal. 71, 5313-5317 (2009)

3. Suzuki, T: Generalized distance and existence theorems in complete metric spaces. J. Math. Anal. Appl. 253, 440-458 (2001)

4. Suzuki, T: Several fixed point theorems concerning $\tau$-distance. Fixed Point Theory Appl. 2004, 195-209 (2004)

5. Tataru, D: Viscosity solutions of Hamilton-Jacobi equations with unbounded nonlinear terms. J. Math. Anal. Appl. 163, 345-392 (1992)

6. Vályi, I: A general maximality principle and a fixed point theorem in uniform space. Period. Math. Hung. 16, 127-134 (1985)

7. Edelstein, M: On fixed and periodic points under contractive mappings. J. Lond. Math. Soc. 37, 74-79 (1962)

8. Chang, SS, Tang, YK, Wang, L, Xu, YG, Zhao, YH, Wang, G: Convergence theorems for some multi-valued generalized nonexpansive mappings. Fixed Point Theory Appl. 2014, 33 (2014)

9. Jleli, M, Samet, B: A new generalization of the Banach contraction principle. J. Inequal. Appl. 2014, 38 (2014)

10. Jleli, M, Karapınar, E, Samet, B: Further generalizations of the Banach contraction principle. J. Inequal. Appl. 2014, 439 (2014)

11. Secelean, NA: Iterated function systems consisting of F-contractions. Fixed Point Theory Appl. 2013, 277 (2013)

\section{Submit your manuscript to a SpringerOpen ${ }^{\circ}$ journal and benefit from:}

- Convenient online submission

Rigorous peer review

- Immediate publication on acceptance

- Open access: articles freely available online

- High visibility within the field

- Retaining the copyright to your article 